\title{
ETHNOGENETIC RELATIONS BETWEEN THE POPULATION OF THE MIDDLE SARMATIAN TIME IN THE EASTERN EUROPEAN STEPPES ${ }^{1}$
}

\author{
Mariya A. Balabanova \\ Volgograd State University, Volgograd, Russian Federation
}

\begin{abstract}
Introduction. The author of the article shows the problem of ethnogenetic relations between the population of the Middle Sarmatian time $\left(1^{\text {st }}\right.$ - the first half of the $2^{\text {nd }} \mathrm{c}$. AD) of the Lower Volga region and the Lower Don. Methods and materials. The author analyzes craniological series of more than 400 skulls for solving this problem. The author uses digital information on the synchronous population (53 male and 47 female craniological series) to identify the ancestor-descendant relationships. The paper shows the comparative analysis carried out with the help of discriminate analysis by the canonical method. The results of the analysis are processed by the multidimensional non-metric scaling and cluster analysis to visualize on the Mahalanobis proximity distance matrix. Analysis. The results of the comparative analysis allow revealing the significant morphological similarity of the Middle Sarmatian territorial groups of the Lower Volga and the Lower Don. This similarity can be primarily explained by the commonality of the Europeoid genetic substrate dating back to the population of the Early Sarmatian time in these regions. In addition to this component, various Eastern components participated in the formation of the anthropological type of the Middle Sarmatian population. In the process of migration and integration these components defined the population's image of the $1^{\text {st }}$ - the first half of the $2^{\text {nd }}$ centuries $\mathrm{BC}$ as the morphological complex. Results. The results of the comparative analysis suggest at least two Eastern components. The first component has mixed Mongoloid-Caucasoid features and its origin is associated with the population of Kazakhstan of the $3^{\text {rd }}-1^{\text {st }}$ centuries BC (presumably with kangyu population) and the Southern Siberia (Pazyryk and Kamenskaya cultures). The second one also has the South Siberian origin (Tagar-tesinsk), but its racial type is defined as a type of long-headed Europeoids.
\end{abstract}

Key words: Middle Sarmatians, diagonal burial type, mezocran type, anthropological type, individual mound, canonical vectors, ethnogenetic relations.

Citation. Balabanova M.A. Ethnogenetic Relations Between the Population of the Middle Sarmatian Time in the Eastern European Steppes. Vestnik Volgogradskogo gosudarstvennogo universiteta. Seriya 4. Istoriya. Regionovedenie. Mezhdunarodnye otnosheniya [Science Journal of Volgograd State University. History. Area Studies. International Relations], 2019, vol. 24, no. 5, pp. 51-66. (in Russian). DOI: https://doi.org/10.15688/ jvolsu4.2019.5.4

УДК 930.26(470+571):711.3

ББК $63.48(2)-3$

Дата поступления статьи: 18.04.2019

Дата принятия статьи: 14.05.2019

\section{ЭТНОГЕНЕТИЧЕСКИЕ СВЯЗИ НАСЕЛЕНИЯ СРЕДНЕСАРМАТСКОГО ВРЕМЕНИ ВОСТОЧНО-ЕВРОПЕЙСКИХ СТЕПЕЙ ${ }^{1}$}

\author{
Мария Афанасьевна Балабанова
}

Волгоградский государственный университет, г. Волгоград, Российская Федерация

Аннотация. В статье рассмотрена проблема этногенетических связей населения среднесарматского времени (I - первая половина II в. н. э.) Нижнего Поволжья и Нижнего Дона. Для решения поставленной перед собой задачи автор проанализировал краниологические серии численностью более 400 черепов. С целью выявления связей типа предок - потомок использовалась цифровая информация по относительно синхронному населению (53 мужские и 47 женских краниологических серий). Сравнительный анализ проводился с помощью дискриминантного анализа каноническим методом. Для визуализации результатов анализа 


\section{АРХЕОЛОГИЯ ВОСТОЧНО-ЕВРОПЕЙСКИХ СТЕПЕЙ}

матрица расстояний близости по Махаланобису обрабатывалась методами многомерного неметрического шкалирования и кластерным анализом. Результаты сравнительного анализа позволили выявить значительное морфологическое сходство территориальных групп среднесарматского населения Нижнего Поволжья и Нижнего Дона. Такое сходство можно, прежде всего, объяснить общностью европеоидного генетического субстрата, восходящего к населению раннесарматского времени этих регионов. Кроме данного компонента в формировании антропологического типа населения среднесарматского времени участвовали различные восточные группы, которые в процессе миграции и других интеграционных процессов, протекающих на основе субстрата, определили морфологический комплекс, характеризующий облик населения I - первой половины II в. н. э. На основе межгруппового анализа можно предположить как минимум два восточных компонента. Первый имеет смешанные монголоидно-европеоидные черты и своим происхождением связан с населением Казахстана III-I вв. до н. э. (предположительно кангюйским населением) и Южной Сибири (пазырыкская и каменская культуры). Второй компонент также имеет южно-сибирское происхождение (тагарско-тесинское), но его расовый тип определяется как тип длинноголовых европеоидов.

Ключевые слова: средние сарматы, диагональный тип захоронения, мезокранный тип, антропологический тип, индивидуальная насыпь, канонические вектора, этногенетические связи.

Цитирование. Балабанова М. А. Этногенетические связи населения среднесарматского времени восточно-европейских степей // Вестник Волгоградского государственного университета. Серия 4, История. Регионоведение. Международные отношения. -2019. - Т. 24, № 5. - С. 51-66. - DOI: https://doi.org/10.15688/ jvolsu4.2019.5.4

Введение. История изучения этногенетических связей населения среднесарматского времени Нижнего Поволжья на основе палеоантропологических материалов начинается с работы В.В. Гинзбурга [8, с. 562, 563], изучившего материалы Калиновского могильника. Характеризуя морфологический тип данной группы кочевников, автор отмечает, что он сходен с типом населения раннесарматского времени. В общей массе черепов исследователь выделяет около 20,0 \% с андроновским краниологическим типом, около 15,0 \% женских черепов со средиземноморским комплексом и один мужской череп смешанного монголоидно-европеоидного типа, напоминающий южно-сибирский. Наличие описанных выше типов В.В. Гинзбург [8, с. 574] связывает с тем, что население было смешанным. Видимо, к “однородной по типу племенной основе примешивались особи или даже целые группы (может быть, семьи или роды) иных антропологических типов”.

Несколько раньше Т.С. Кондукторова $[12$, с. 170, 171] изучила две локальные группы сарматов Украины (запорожская и днепропетровская). Как показала проверка дат погребений, откуда происходил ее материал, все они среднесарматского времени. Обе серии обладают сходством. Мезобрахикранный тип у них сочетается с широким средневысоким лицом, горизонтальная профилировка которого умеренная, а угол выступания носа резкий. Сравнивая эти группы с известными на то время двумя локальными сарматскими группами, изученными Г.Ф. Дебецом [9], она отмечает их большое сходство с саратовской группой. Об этом пишет и Б.В. Фирштейн $[14$, c. 109$]$, сравнивая их со своими более массовыми материалами.

На этих материалах Б.В. Фирштейн подробно рассматривала вопросы соотношения сарматских хронологических групп между собой и с синхронным населением восточнее Волги [14, с. 95, 117, 123, 124]. Прежде всего, автор отмечает сходство мужского населения раннесарматского и среднесарматского периодов и отличие его от позднесарматского. Что касается женских серий раннего и среднего этапов, то Б.В. Фирштейн отмечает лишь отличия их по черепному указателю: в раннесарматской серии преобладают брахикранные формы, а в среднесарматской серии мезокранные. Сходство населения первых двух хронологических групп, по ее мнению, связано их генетической преемственностью.

Для определения этногенетических связей сарматских групп Б.В. Фирштейн проводит сравнение с синхронным населением Средней Азии и Южной Сибири. Результаты сопоставления с усунями Казахстана, группой шибинского этапа Предгорного Алтая, сериями тагарской и таштыкской культур Южной Сибири и т. д. показали, что только группа из шибинского этапа Предгорного Алтая обла- 
дает наибольшим сходством с сарматским населением. К сожалению, в межгрупповых сопоставлениях Б.В. Фирштейн не выделяет отдельно группу среднесарматского времени, а выводы, сделанные ею, относятся к суммарной выборке, включающей черепа без следов деформации всех трех периодов сарматской культуры.

Для решения проблемы этногенетических связей среднесарматского населения мною были использованы суммированные данные по опубликованным и новым материалам из могильников Нижнего Поволжья и Нижнего Дона [2]. Внутригрупповой полиморфизм населения позволил выделить морфологический комплекс, который можно связать с субстратным раннесарматским населением, и комплекс пришлых групп. Так, для населения Заволжья характерно преобладание раннесарматского типа. Что касается группы из Волго-Донского междуречья, то в ее облике сочетаются мезоморфные черты с ослабленной горизонтальной профилировкой лица на обоих уровнях при среднем угле выступания носа. Группа из могильников Астраханского правобережья - тип длинноголовых европеоидов [2, c. $97,100,107,112,118,126]$. На основе этих данных была предложена концепция формирования среднесарматской культуры и населения, которое связано с процессами смешения субстратных раннесарматских компонентов с пришлыми, предположительно восточными элементами [2, с. 125].

Так как диагональный тип захоронения, наличие захоронений под индивидуальными насыпями и элитных захоронений являются культурными новациями среднесарматского времени, то для выявления этногенетических связей предпринимались попытки изучения антропологического типа групп, сформированных по этим археологическим критериям $[3 ; 4 ; 5 ; 6]$.

Как показал анализ серии, полученной из погребений с диагональным типом погребения умершего, она обладает внутригрупповой неоднородностью и включает типы широкоголовых и длинноголовых европеоидов. Первый тип генетически связан с субстратным раннесарматским населением, а второй - с типом мигрантов, которые принесли эту традицию [3, с. 85]. Специфика территориальных групп показала, что две серии из могильников доно-аксайского и заволжского регионов характеризуются типом длинноголовых европеоидов, который можно связать с мигрантами. Маршрут последних пролегал с одной стороны через Заволжье по Северному Каспию, а с другой - через кавказские проходы.

На основе сопоставления групп среднесарматского и позднесарматского времени из диагональных погребений удалось проследить и процессы взаимодействия различных по своему происхождению групп кочевого населения $[6$, с. 60,65$]$. Так, присутствие брахикранного компонента в краниотипе «диагональников», с одной стороны, может указывать на использование этого обряда автохтонным населением, связанным с раннесарматским субстратом, а с другой - на то, что наряду с длинноголовыми группами в миграциях могли участвовать и широкоголовые. Миграционный характер брахикранного компонента подтверждается тем, что он сочетается с большей уплощенностью горизонтальной профилировки лицевого скелета на обоих уровнях. Этот морфологический тип преобладает у населения гунно-сарматского времени Южной Сибири. В связи с тем, что диагональный обряд продолжали практиковать и племена позднесарматского времени, во второй половине II начале III в. н. э., сложная картина взаимодействия соотносится с тем, что, видимо, пришлые группы позднесарматского облика через брачные контакты или по другим причинам восприняли традицию диагональных захоронений. Описанная ситуация позволяет выдвинуть и другую гипотезу, касающуюся статусной позиции диагональных захоронений, которая может отражать мировоззренческие ориентиры. Этот оригинальный обряд явно был одним из признаков религиозной революции, которую принесли мигранты в Южное Приуралье, на Нижнюю Волгу и на Нижний Дон.

Результаты исследования серий среднесарматского времени из комплексов под индивидуальными насыпями и из курганов-кладбищ позволяют сформулировать ряд положений, которые в какой-то степени помогут решить проблему происхождения среднесарматской культуры и населения [4, с. 578]. Первое, на что следует обратить внимание, - морфо- 


\section{АРХЕОЛОГИЯ ВОСТОЧНО-ЕВРОПЕЙСКИХ СТЕПЕЙ}

логический тип погребенных под индивидуальными насыпями - он мало отличается от типа погребенных в курганах-кладбищах, что, видимо, явилось не результатом глобальных миграций, а изменением, носившим мировоззренческий характер. Региональное распределение антропологических материалов показывает резкое отличие групп из индивидуальных захоронений могильников Астраханского правобережья и из погребений курганов-кладбищ ВолгоДонского междуречья. Видимо, как в первом, так и во втором случае, перед нами антропологический тип возможных мигрантов, который в первом случае диагностируется как тип длинноголовых европеоидов, а во втором - как тип, сочетающий мезокранию с умеренной горизонтальной профилировкой лица и носа.

Компонент местного населения раннесарматского облика, видимо, присутствует в обеих группах из Заволжья (группы из индивидуальных погребальных комплексов и из курганов-кладбищ), в материалах могильников Украины и в некоторой степени в материалах нижнедонских могильников. Сохранение у населения среднесарматского времени западных регионов локализации памятников (Нижний Дон, Украина) раннесарматского компонента можно объяснить с позиций политической ситуации, которая была связана с массовым перемещением сарматских племенных образований на рубеже эр в I в. н. э. в западном направлении. Информация об этих событиях приводится в античных письменных источниках (Страбон, Плиний Старший, Птолемей и др.).

Распределение антропологического материала по типам погребальных конструкций показывает резкое отличие серий, полученных из диагональных захоронений, от могил с подквадратной конструкцией [4, с. 577, 578]. Данный обряд, видимо, практиковала какая-то группа, занимающая достаточно высокий социальный статус, так как в больших могилах квадратной и подквадратной формы с положением умершего по оси могилы содержится богатый набор инвентаря, а самые богатые комплексы среднесарматского времени сооружались именно в могилах такой формы. Что касается диагональных захоронений, то, видимо, статус погребенных в них людей был ниже, чем в могилах с положением по оси [4, c. 577,578$]$. К этому выводу пришли археоло- ги (М.П. Абрамова, И.П. Засецкая, Е.К. Максимов, А.С. Скрипкин, А.А. Глухов и др.), проанализировавшие половозрастную структуру диагональных погребений. Специфика их такова, что позволяет говорить о профессиональной направленности отдельных членов сарматского общества: части мужчин как воинов и части женщин как «жриц».

Антропологический тип среднесарматской элиты изучался на серии, насчитывающей 11 черепов (6 мужских и 5 женских) [5, с. 37]. Мужская серия из элитных погребальных комплексов по сравнению с суммарной среднесарматской демонстрирует большую массивность и большую внутригрупповую неоднородность. Что касается женских серий, то, хотя обе сравниваемые группы и отличаются между собой, различий меньше, чем при сравнении мужских серий.

Подробную характеристику населения этого времени Нижнего Дона дает Е.Ф. Батиева [7, с. 60-64]. В ее работе фигурируют две выборки среднесарматского времени: ранний период (I в. до н. э. - I в. н. э.) и поздний период (I-II вв. н. э.). Сравнивая их между собой и с раннесарматской группой, она отмечает специфику мужских черепов из более ранних погребений (І в. до н. э. - І в. н. э.). По сравнению с раннесарматской и поздней среднесарматской группами у них самые малые размеры лицевых признаков.

Серия позднего периода I-II вв. н. э. отличается самым широким и наиболее уплощенным в подносовой области лицом и высокими орбитами. По сравнению с предшествующими группами (раннесарматской и раннего периода среднесарматской культуры) эта, по мнению Е.Ф. Батиевой [7, с. 6072], занимает промежуточное положение в зависимости от отдельных характеристик мозгового и лицевого отделов черепа. Тем не менее ею отмечается большее сходство обеих среднесарматских серий между собой и сходство их с позднесарматской, чем с черепами из раннесарматских погребений. Распределение коррелятивных связей между углами горизонтальной профилировки лица с некоторыми признаками мозгового и лицевого отделов в поздней среднесарматской группе позволяет автору выделить краниологический тип, предполагающий незначитель- 
ную монголоидную примесь. Обе серии на фоне синхронных тяготеют к сериям из Поволжья и Украины.

Таким образом, обзор антропологической литературы показал, что проблема этногенетических связей среднесарматского населения на массовых материалах рассматривалась около 20 лет назад. За это время почти вдвое увеличилась численность среднесарматской выборки из могильников Нижнего Поволжья, появились публикации по антропологии среднесарматского населения Нижнего Дона, а также увеличился сравнительный материал по другим несарматским группам оседлого и кочевого населения Евразийской степи. В связи с этим возникает необходимость пересмотреть данную проблему с учетом новых сведений. Кроме того, тема продолжает разрабатываться и на археологическом материале [13].

Материал и методика исследования. Для определения этногенетических связей были суммированы краниологические материалы среднесарматского времени по могильникам Нижнего Поволжья, серия насчитывает 296 черепов (180 мужских и 116 женских); по могильникам Нижнего Дона - 103 черепа (54 мужских и 49 женских); по могильникам Украины - 37 (19 мужских и 18 женских).

Весь представленный в работе материал изучался методами, принятыми в российской антропологии $[1 ; 10$; и др.]. Характер хронологической и региональной изменчивости определялся с помощью методов статистической проверки гипотез. Результаты обсуждаемых исследований анализировались на основе расстояний Махаланобиса, рассчитанных по средним групповым данным четырнадцати краниометрических признаков с поправкой на численность наблюдений. Программа перечня признаков является традиционной для межгрупповых сопоставлений и включает в себя 14 признаков (см. таблицу). Для визуализации результатов на двухмерных графиках расстояния Махаланобиса преобразовывались в координаты методом многомерного шкалирования по алгоритму Гуттмана и кластерным анализом (рис. 1-4).

В межгрупповой анализ были включены преимущественно суммарные данные по пятидесяти двум мужским и сорока шести жен- ским сериям с территории степной полосы Евразии.

Результаты исследования и обсуждение. Как показывают результаты канонического анализа, для выявления межгрупповых зависимостей наиболее интересными представляются первые два канонические вектоpa, на которые приходится более 60,0 \% межгрупповой изменчивости (64,0 \% при анализе мужских и около 63,0 \% при анализе женских групп). Общий вклад в межгрупповую изменчивость первого канонического вектора (далее - КВ) в разнополых группах более $40,0 \%$, и он является переменной, разграничивающей два расовых комплекса. Высокие корреляции приходятся на следующие признаки:

- поперечный диаметр черепа (8 размер, положительная корреляция) и продольный диаметр черепа, наименьшая ширина лба, угол выступания носа (номера по Мартину: 1; 9; 75-1 размеры, отрицательная корреляция) у мужчин;

- поперечный диаметр черепа и верхняя высота лица $(8,48$, положительная корреляция) и продольный диаметр черепа (1 размер, отрицательная корреляция) у женщин.

Таким образом, распределение межгрупповой изменчивости в разнополых группах совпадает и на положительном полюсе разместились серии со смешанным монголоидно-европеоидным комплексом, сочетающим короткую широкую мозговую коробку с узким лбом и слабо выступающим носом (популяции Центральной Азии: хунны Монголии, группа из могильника Аймырлыг, серия тасмолинской культуры Центрального Казахстана и др.). На отрицательном полюсе оказались серии с европеоидным долихокранным комплексом (популяции с территории Южной Сибири: тагарско-тесинские серии и популяции с территории Восточной Европы: скифские, черняховские и позднесарматские серии. На графике неметрического номерного шкалирования эти два скопления заняли зеркальное положение (рис. 1, 2). Что касается исследуемых среднесарматских групп, то все три (нижневолжская и две нижнедонские) имеют отрицательные значения по КВ I. На графике они также располагаются в центре в окружении раннесарматских серий (рис. 1,2 ).

Несмотря на то что КВ II в обеих разнополых группах имеет меньший вклад в меж- 


\section{АРХЕОЛОГИЯ ВОСТОЧНО-ЕВРОПЕЙСКИХ СТЕПЕЙ}

групповую изменчивость, стоит отметить, что эта переменная выделяет мужские группы с широким лбом и глазницей от групп с узким лбом и глазницей (9 и 51 признаки). Первый комплекс является специфической особенностью ранних кочевников Западного Казахстана, Южного Приуралья, Нижнего Поволжья и Нижнего Дона VI-III вв. до н. э. Второй комплекс, то есть группы с узким лбом и глазницей, встречается как у европеоидов (серии черняховской культуры), так и у популяций с монголоидной примесью (хунны Монголии и «жители гунно-сарматского времени» Тувы). Мужские среднесарматские группы из территории Нижнего Поволжья и Нижнего Дона по этой переменной занимают разные позиции. Нижневолжская среднесарматская группа располагается по соседству с нижневолжской раннесарматской (II-I вв. до н. э.) и ранней среднесарматской группой из могильников Нижнего Дона. Поздняя группа среднесарматской культуры из могильников Нижнего Дона имеет отрицательное значение по КВ II и по этой паре признаков обладает сходством с позднесарматской группой Нижнего Дона, с некоторыми группами черняховской культуры и тагарско-тесинскими.

У женщин несколько иное сочетание признаков по КВ II: широкий лоб сочетается с низким лицевым скелетом (9 и 48 размеры). В этом случае также максимальные значения имеют савромато-раннесарматские серии, а противоположный набор признаков представлен в сериях с монголоидным комплексом (хунны Монголии, Аймырлыг, Яншао и др.). Все три женские среднесарматские группы из могильников Нижнего Поволжья и Нижнего Дона имеют положительные значения по КВ II и располагаются среди серий савромато-раннесарматского времени.

Результаты многомерного неметрического шкалирования, согласованные с итогами кластерного анализа, позволяют определить зоны трансгрессии населения раннесарматского, среднесарматского и позднесарматского времени. В центре графиков анализа разнополых групп разделение этих совокупностей достаточно надежно. Показательно, что при применении как метода многомерного шкалирования, так и кластерного анализа, мужские группы раннесарматского и среднесар- матского времени располагаются более компактно, чем женские, независимо от географической принадлежности, что еще раз подтверждает гипотезу о раннесарматской субстратной основе антропологического типа среднесарматского населения (рис. 1) [14, с. $95 ; 2$, с. $111 ; 7$, с. 64$]$.

Что касается женских групп, то результаты кластерного анализа особо отделяют группу из ранних погребений среднесарматской культуры (I в. до н. э. - І в. н. э.) могильников Нижнего Дона от остального раннесреднесарматского массива. По табличным данным, приведенным в работе Е.Ф. Батиевой [7, с. 62], эта группа более широкоголовая, широколицая и с ослабленной горизонтальной профилировкой в подносовой области, чем раннесарматская и поздняя группа среднесарматской культуры (I-II вв. н. э.).

Следует также отметить, что по результатам нашего анализа женские позднесарматские группы Нижнего Поволжья сохраняют основной раннесарматский субстратный комплекс, это демонстрирует график (рис. 2).

Для выделения «несарматских» морфологических комплексов, участвовавших в формировании исследуемого населения, была проведена серия дискриминантных анализов с исключением из анализа савроматских, раннесарматских и позднесарматских серий. В результате канонического анализа сохраняется высокая нагрузка на КВ I: 48,5 \% при анализе мужских серий и 47,7 \% при анализе женских серий. Вклад КВ II несколько снижается: 16,7 \% при анализе мужских серий и 15,3 \% при анализе женских серий. Высокие нагрузки по обоим каноническим векторам выпадают на те же признаки, что и в предыдущем случае (см. таблицу).

Результат многомерного неметрического шкалирования и кластерного анализа расстояний близости Махаланобиса демонстрирует большое сходство и обособление всех мужских серий среднесарматского времени от остального массива. С одной стороны, к ним примыкают тагарско-тесинские группы Минусинской котловины и скифские-Восточной Европы, а с другой - группы ранних кочевников Западного Казахстана и пазырыкские. Несмотря на это, отмечается их (мужских серий среднесарматского времени) большее 
сходство с тагарско-тесинским населением (рис. 3).

Результаты анализа женских серий среднесарматского времени также демонстрируют сходство между собой, а включение в их кластер группы из поздних погребений ранних кочевников Западного Казахстана (III-I вв. до н. э.) может свидетельствовать о присутствии у них кангюйского компонента $[11$, с. 182] (рис. 4). Не исключается и участие в формировании женского населения также западнои южно-сибирских синхронных групп (население каменской, саргатской и пазырыкской культур).

Заключение. Как свидетельствуют письменные источники (Страбон, Плиний Старший, Иосиф Флавий, Птолемей и др.), на рубеже эр и в первых веках н. э. в восточноевропейских степях протекали значительные этнические перемещения, связанные с процессами миграции, смешения и вытеснения отдельных (в том числе и сарматских) племенных союзов в западные регионы. Эти миграции с востока (казахстанский, южно-сибирский и заволжский регион) в какой-то степени реконструируются результатами анализа антропологических материалов среднесарматского времени.

Так, краниологические серии этого времени позволяют определить морфологический тип населения, который имеет характерные специфические черты, отличающие его от раннесарматского (II-I вв. до н. э.). Отличия связаны с преобладанием мезокранных форм мозговой коробки и умеренной профилировки лица по обоим горизонтальным углам. На отдельных территориях (юг Волго-Донского междуречья) такая профилировка гармонирует со средним углом выступания носа, что предполагает приход на территорию Нижнего Поволжья инородных групп восточного происхождения (южно-сибирского?). Антропологическая специфика групп населения с других территорий (Заволжье, Нижний Дон и Украина) позволяет говорить в первом случае (регион Заволжья) о сохранении основного типа субстратного раннесарматского населения, а во втором (Нижний Дон и Украина) о перемещении населения раннесарматского облика на запад в нижнедонские и северо-причерноморские степи. В этих группах комплекс мигрантов проявляется слабо и улавливается по углу профилировки лица в подносовой области. Еще один морфологический комплекс, который тоже может быть пришлым, демонстрирует группа из могильников Астраханского правобережья. Сочетание признаков позволяет определить его расовый тип как тип длинноголовых европеоидов, преобладающий в последующую, позднесарматскую эпоху. Скорее всего, этот комплекс также восточного происхождения и имеет аналоги среди населения Минусинской котловины (тагарская и тесинская культуры).

Наличие восточного «кангюйского» компонента (территория Казахстана) в морфологическом типе среднесарматского населения подтверждается и палеогенетическим анализом [15]. Несмотря на чрезвычайную привлекательность данного вывода, следует отметить, что только два образца из восьми, включенных в анализ, дают сходство с материалами Казахстана. Надеемся, что исследования в этой области, которые сейчас ведутся на массовых материалах, позволят более подробно рассматривать проблему этногенетических связей всех трех хронологических групп сарматского населения.

В заключение хотелось бы отметить, что поиски этногенетических связей среднесарматского населения Нижнего Поволжья, Нижнего Дона и Украины как подтвердили ряд известных уже положений, так и позволили сформулировать новые:

1) наблюдается определенное подобие всех среднесарматских групп, что свидетельствует о сходных морфологических компонентах, которые формировали облик населения рубежа эр (I - первой половины II в. н. э.);

2) несмотря на морфологическую близость среднесарматских и раннесарматских серий (у них у всех есть общий брахикранный европеоидный тип с умеренной профилировкой лицевого скелета на верхнем уровне), повсюду отмечается взаимовлияние пришлых групп и местного населения, которые формировали облик среднесарматского населения отдельных территорий;

3) «восточный компонент», предположительно с монголоидной примесью, лучше представлен на материалах могильников южной части Волго-Донского междуречья; 


\section{АРХЕОЛОГИЯ ВОСТОЧНО-ЕВРОПЕЙСКИХ СТЕПЕЙ}

4) еще один восточный компонент, но характеризующийся типом длинноголовых европеоидов, видимо, связан с тагарско-тесинской антропологической формацией;

5) сходство с группой III-I вв. до н. э. с территории Казахстана как по комплексу краниологических признаков, так и по результатам палеогенетического анализа, позволяет предположить кангюйский компонент, участвовавший в формировании среднесарматского населения;

6) пришлые группы в восточных сарматских провинциях (Заволжье, Волго-Донское междуречье), видимо, приводили к перемещениям групп людей раннесарматского облика в западном направлении (Нижний Дон, Северное Причерноморье).

\section{ПРИМЕЧАНИЕ}

${ }^{1}$ Статья выполнена в рамках Государственного задания Минобрнауки РФ, проект № 33.2830.2017/4.6 «Юг России в эпоху раннего железного века: диалог культур Восток - Запад».

The reported article was carried out in the framework of the state task of the Ministry of Science and Higher Education of the Russian Federation, project number 33.2830.2017/4.6 "South of Russia in the Early Iron Age: Dialogue of East and West Cultures". 
М.А. Балабанова. Этногенетические связи населения среднесарматского времени

ПРИЛОЖЕНИЕ

Элементы первых двух канонических векторов для 53 мужских и 47 женских серий раннего железного века

Elements of the first two canonical vectors for 53 male and 47 female series of the Early Iron Age

\begin{tabular}{|c|c|c|c|c|}
\hline \multirow{2}{*}{$\begin{array}{c}\text { № по Мартину } \\
\text { и др. }\end{array}$} & \multicolumn{2}{|c|}{ Мужчины } & \multicolumn{2}{c|}{ Женщины } \\
\cline { 2 - 5 } I & II & I & II \\
\hline 1 & $\mathbf{- 0 . 5 8 2}$ & -0.072 & $\mathbf{- 0 . 7 1 9}$ & -0.189 \\
\hline 8 & $\mathbf{0 . 5 9 9}$ & 0.384 & $\mathbf{0 . 6 6 3}$ & 0.358 \\
\hline 17 & -0.149 & -0.337 & -0.130 & -0.139 \\
\hline 9 & $\mathbf{- 0 . 5 1 9}$ & $\mathbf{0 . 4 5 4}$ & -0.424 & $\mathbf{0 . 4 8 3}$ \\
\hline 45 & 0.204 & -0.043 & 0.181 & 0.093 \\
\hline 48 & 0.137 & -0.257 & $\mathbf{0 . 4 7 1}$ & $\mathbf{- 0 . 6 1 0}$ \\
\hline 55 & 0.082 & -0.169 & -0.122 & -0.007 \\
\hline 54 & 0.100 & -0.145 & 0.114 & -0.091 \\
\hline 51 & 0.283 & $\mathbf{0 . 4 9 8}$ & 0.407 & 0.203 \\
\hline 52 & 0.056 & -0.264 & -0.062 & -0.081 \\
\hline 77 & 0.181 & 0.068 & 0.083 & -0.287 \\
\hline zm & 0.297 & -0.193 & 0.336 & -0.187 \\
\hline SS: SС & 0.119 & 0.425 & 0.043 & 0.400 \\
\hline $75(1)$ & $\mathbf{- 0 . 5 1 6}$ & 0.242 & -0.233 & 0.258 \\
\hline Собственные & 65.012 & 27.448 & 38.496 & 16.276 \\
числа & & & & \\
\hline \% дисперсии & 44.969 & 18.986 & 43.938 & 18.576 \\
\hline
\end{tabular}




\section{АРХЕОЛОГИЯ ВОСТОЧНО-ЕВРОПЕЙСКИХ СТЕПЕЙ}

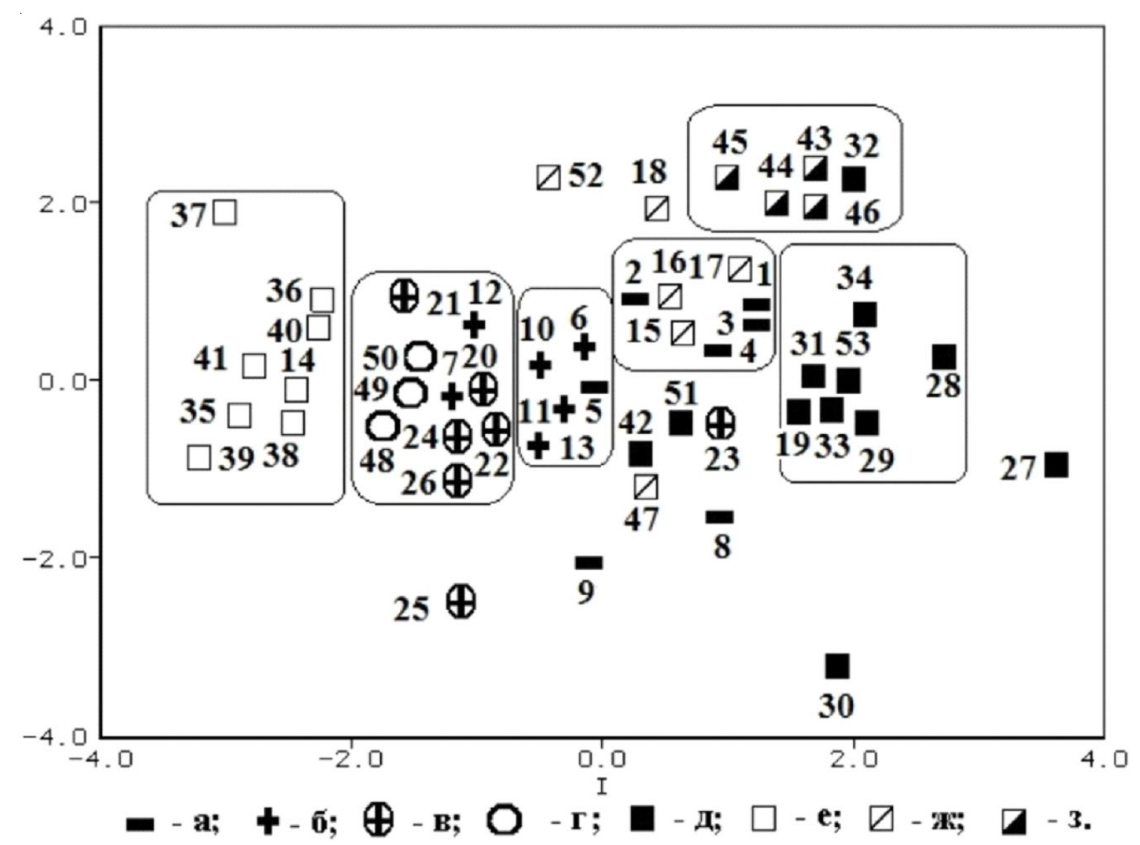

Рис. 1. Результат межгруппового многомерного неметрического шкалирования и кластерного анализа расстояний Махаланобиса $\left(\mathrm{D}^{2}\right) 53$ мужских краниологических серий:

( $a$ - серии савромато-раннесарматские; $\sigma$ - сарматские серии первых веков нашей эры; в - тагарско-тесинсо-таштыкские серии; 2 - скифские серии, могильники Северного Причерноморья; $\partial$ - южно-сибирские и центрально-азиатские серии; в - черняховские серии; ж- серии с территории Казахстана и Средней Азии;

3 - серии саргатской культуры [объединены группы, образующие один кластер]).

Савромато-сарматские серии: 1 - Южное Приуралье, VI-IV вв. до н. э.; 2 - Нижнее Поволжье, VI-IV вв. до н. э.; 3 - Южное Приуралье, IV-III вв. до н. э.; 4 - Нижнее Поволжье, IV-III вв. до н. э.; 5 - Нижнее Поволжье, II-I вв. до н. э.;

6 - Нижнее Поволжье, I - первая половина II в. н. э.; 7 - Нижнее Поволжье, вторая половина II-IV вв. н. э.;

8 - Нижний Дон, VI-III вв. до н. э.; 9 - Нижний Дон, III-I вв. до н. э.; 10 - Нижний Дон, І в. до н. э. - I в. н. э.;

11 - Нижний Дон, I-II вв. н. э.; 12 - Нижний Дон, II-IV вв. н. э.; 13 - Украина; 14 - Херсонес (первые века нашей эры).

Ранний железный век Казахстана: 15 - кочевники, VI-IV вв. до н. э.; 16 - кочевники, IV-III вв. до н. э.;

17 - кочевники, III-І вв. до н. э.; 18 - тасмолинская культура (сум.); 19 - гунно-сарматское время, Предгорный Алтай (сум.). Тагарская культура: 20 - подгорновский этап; 21 - биджинский этап; 22 - сарагашенский этап;

23 - тесинское время, склепы; 24 - тесинское время, грунтовые могилы; 25 - таштыкская культура (сум.);

26 - тесинско-таштыкский этап (сум.); 27 - хунны Монголии; 28 - Аймырлыг XXXI (III-I вв. до н. э.);

29 - Кокэль (І в. до н. э. - V в. н. э.); 30 - гунно-сарматское время Тува; 31 - усуни Тянь-Шаня; 32 - каменская культура (сум., III-II - начало І в. до н. э.).

Пазырыкская культура: 33 - суммарная серия; 34 -Тянь-Шань.

Черняховская культура: 35 - Среднее Приднепровье; 36 - Левобережная Украина; 37 - Западная Украина; 38 - Буджак; 39 - Южный Буг-Тилигул; 40 - Нижнее Поднепровье; 41 - Молдавия; 42 - Кызыл-Джар. Саргатская культура: 43 - междуречье Исеть-Тобол; 44 - Приишимье; 45 - Прииртышье; 46 - Бараба; 47 - Кенкольская культура (сум., I-IV вв.).

Скифское время, Северное Причерноморье: 48 - Левобережная Украина; 49 - Правобережная Украина; 50 - поздний период (сум.); 51 - Казыбаба (VI-IV вв. до н. э.). Сакская культура: 52 - Сакар-Чага I; 53 - Тянь-Шань (сум.)

Fig. 1. The result of intergroup multidimensional non-metric scaling and cluster analysis of Mahalanobis distances $\left(\mathrm{D}^{2}\right)$ of 53 male craniological series:

( $a$ - Savromato-Early-Sarmatian series; $\sigma$ - Sarmatian series of the first centuries AD; в - Tagar-Tesin-Tashtyk series; 2 - Scythian series, burials of the Northern Black Sea region; $\partial-$ series from Southern Siberia and Central Asia; $e$ - Chernyakhov series; $\varkappa$ - series from the territory of Kazakhstan and Central Asia; 3 - series of the Sargat culture; [groups forming one cluster are combined]).

Savromato-Sarmatian series: 1 - Southern Urals, $6^{\text {th }}-4^{\text {th }}$ c. BC; 2 - Lower Volga Region, $6^{\text {th }}-4^{\text {th }} \mathrm{c}$. BC; 3 - Southern Urals, $4^{\text {th }}-3^{\text {rd }}$ c. BC; 4 - Lower Volga region, $4^{\text {th }}-3^{\text {rd }}$ c. BC; 5 - Lower Volga region, $2^{\text {nd }}-1^{\text {st }}$ c. BC; 6 - Lower Volga region, $1^{\text {st }}-$ the first half of the $2^{\text {nd }} c . A D ; 7$ - Lower Volga region, the second half of the $2^{\text {nd }}-4^{\text {th }} c . A D$; 
8 - Lower Don region, $6^{\text {th }}-3^{\text {rd }}$ c. $\mathrm{BC} ; 9$ - Lower Don region, $3^{\text {rd }}-1^{\text {st }}$ c. $\mathrm{BC}$;

10 - Lower Don region, $1^{\text {st }}$ c. $\mathrm{BC}-1^{\text {st }} \mathrm{c}$. $\mathrm{AD} ; 11-$ Lower Don region, $1^{\text {st }}-2^{\text {nd }} \mathrm{c} . \mathrm{AD}$;

12 - Lower Don region, $2^{\text {nd }}-4^{\text {th }} \mathrm{c}$. $\mathrm{AD} ; 13$ - Ukraine; 14 - Chersonesus (first centuries $\mathrm{AD}$ ).

Early Iron Age of Kazakhstan: 15 - nomads, $6^{\text {th }}-4^{\text {th }} \mathrm{c}$. BC; 16 - nomads, $4^{\text {th }}-3^{\text {rd }} \mathrm{c}$. BC;

17 - nomads, $3^{\text {rd }}-1^{\text {st }} \mathrm{c}$. BC; 18 - Tasmolin culture (total series); 19 - Hun-Sarmatian period, foothill Altai (total series).

Tagar culture: 20 - Podgornovskiy stage; 21 - Bidzhinskiy stage; 22 - Saragashenskiy stage;

23 - Tesin period, crypts; 24 - Tesin period, ground burials; 25 - Tashtyk culture (total series);

26 - Tesinsin-Tashtyk stage (total series); 27 - Huns of Mongolia; $28-$ Aymyrlyg XXXI $\left(3^{\text {rd }}-1^{\text {st }} \mathrm{c}\right.$. BC);

29 - Kokel $\left(1^{\text {st }}\right.$ c. BC $-5^{\text {th }}$ c. AD); 30 - Hun-Sarmatian time of Tuva; $31-$ Usuni of the Tien Shan;

32 - Kamensk culture (total series, $3^{\text {rd }}-2^{\text {nd }} c$. BC).

Pazyryk culture: 33 - total series; 34 -Tien Shan.

Chernyakhov culture: 35 - Middle Dnieper; 36 - Left-bank Ukraine; 37 - Western Ukraine;

38 - Budjak; 39 - Southern Bug-Tiligul; 40 - Lower Dnieper; 41 - Moldova; 42 - Kyzyl-Dzhar.

Sargat culture: 43 - Iset-Tobol interfluve; 44 - Ishim river territory; 45 - Irtysh river territory; 46 - Baraba; 47 - Kenkol culture (total series, $1^{\text {st }}-4^{\text {th }}$ c. AD).

Scythian period, Northern Black Sea Region: 48 - Left-bank Ukraine; 49 - Right-bank Ukraine; 50 - late period (total series); $51-$ Kazibaba I $\left(6^{\text {th }}-4^{\text {th }} \mathrm{c}\right.$. BC).

Sak culture: 52 - Sakar-Chaga I; 53 - Tien Shan (total series) 


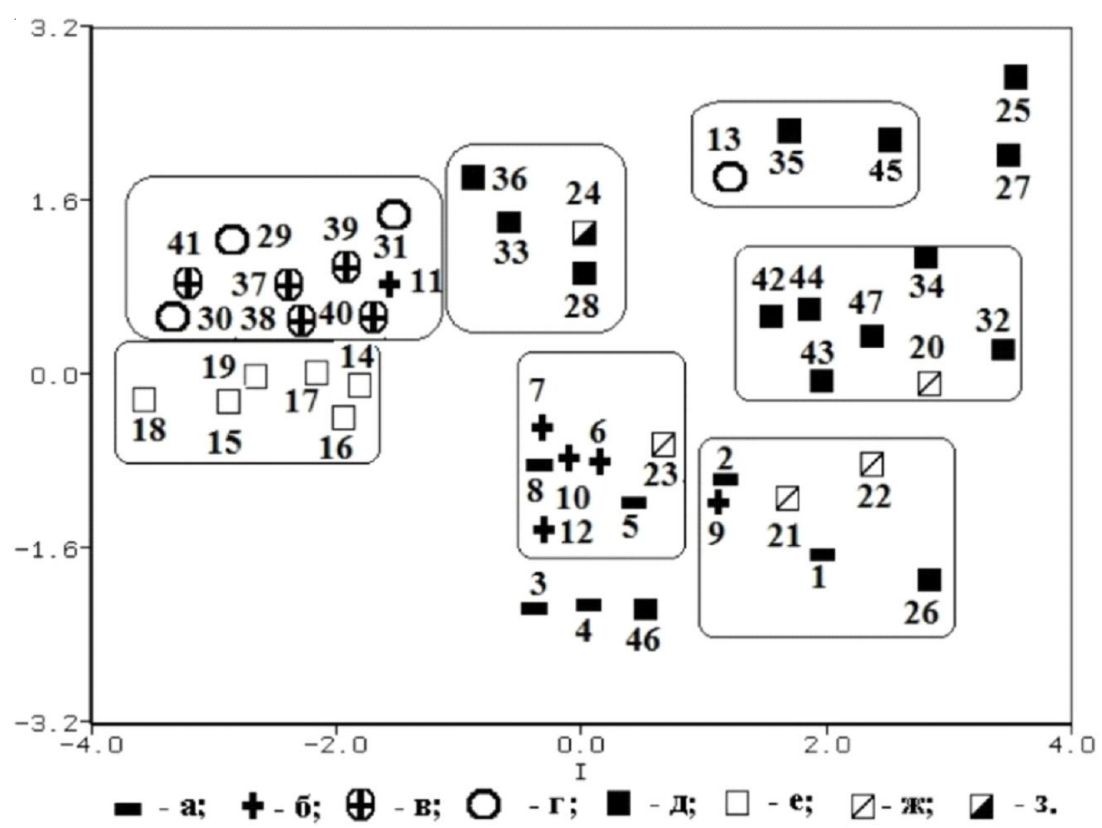

Рис. 2. Результат межгруппового многомерного неметрического шкалирования и кластерного анализа расстояний Махаланобиса $\left(\mathrm{D}^{2}\right) 47$ женских краниологических серий (обозначения на рис. 1-4 совпадают):

Савромато-сарматские серии: 1 - Южное Приуралье, VI-IV вв. до н. э.; 2 - Южное Приуралье, IV-III вв. до н. э.; 3 - Нижнее Поволжье, VI-IV вв. до н. э.; 4 - Нижнее Поволжье, IV-III вв. до н. э.; 5 - Нижнее Поволжье, II-I вв. до н. э.;

6 - Нижнее Поволжье, I - первая половина II в. н. э.; 7 - Нижнее Поволжье, вторая половина II-IV вв. н. э.;

8 - Нижний Дон III-I вв. до н. э.; 9 - Нижний Дон, I в. до н. э. - I в. н. э.; 10 - Нижний Дон, I-II вв. н. э.; 11 - Нижний Дон, II-IV вв. н. э.; 12 - Украина; 13 - Херсонес (первые века нашей эры).

Черняховская культура: 14 - Среднее Приднепровье; 15 - Левобережная Украина; 16 - Западная Украина; 17 - Южный Буг-Тилигул; 18 - Молдавия; 19 - Нижнее Поднепровье.

Ранний железный век Казахстана: 20 - Тасмолинская культура; 21 - кочевники, VI-IV вв. до н. э.; 22 - кочевники, IV-III вв. до н. э.; 23 - кочевники, III-I вв. до н. э.; 24 - саргатская культура (сум.); 25 - Янашао;

26 - Копто; 27 - Догээ-Баары I (VI-IV вв. до н. э.); 28 - каменская культура (сум., III-II - начало I в. до н. э.).

Скифское время, Северное Причерноморье: 29 - Левобережная Украина; 30 - Правобережная Украина;

31 - поздний период (сум.); 32 - Чжоу; 33 - пазырыкская культура (сум.); 34 - Аржан-2 (VII в. до н. э.). Пазырыкская культура: 35 - Майма; 36 - Кызыл-Джар.

Тесинская культура (II в. до н. э. - I в. н. э.): 37 - Черное Озеро; 38 - Есино; 39 - Каменка;

40 - тагарско-таштыкская культура (сум.); 41 - таштыкская культура (сум.); 42 - гунно-сарматское время Тувы (сум.); 43 - Аймырлыг XXXI (III-I вв. до н. э.); 44 - Кокэль (І в. до н. э. - V в. н. э.);

45 - гунно-сарматское время, Предгорный Алтай; 46 - Сакар-Чага I; 47 - хунны Монголии

Fig. 2. The result of intergroup multidimensional non-metric scaling and cluster analysis of Mahalanobis distances $\left(\mathrm{D}^{2}\right)$ of 47 female craniological series (symbols in Fig. 1 and Fig. 2, 3, 4 match):

Savromato-Sarmatian series: 1 - Southern Urals, $6^{\text {th }}-4^{\text {th }}$ c. BC; 2 - Southern Urals, $4^{\text {th }}-3^{\text {rd }} c$. BC; 3 - Lower Volga region, $6^{\text {th }}-4^{\text {th }}$ c. BC; 4 - Lower Volga region, $4^{\text {th }}-3^{\text {rd }}$ c. BC;

5 - Lower Volga region, $2^{\text {nd }}-1^{\text {st }} \mathrm{c}$. BC; 6 - Lower Volga region, $1^{\text {st }}-$ the first half of the $2^{\text {nd }} \mathrm{c} . \mathrm{AD}$;

7 - Lower Volga region, the second half of the $2^{\text {nd }}-4^{\text {th }} \mathrm{c}$. $\mathrm{AD} ; 8$ - Lower Don region, $3^{\text {rd }}-1^{\text {st }} \mathrm{c}$. BC; 9 - Lower Don region, $1^{\text {st }} \mathrm{c} . \mathrm{BC}-1^{\text {st }} \mathrm{c}$. $\mathrm{AD} ; 10-$ Lower Don region, $1^{\text {st }}-2^{\text {nd }} \mathrm{c} . \mathrm{AD}$;

11 - Lower Don region, $2^{\text {nd }}-4^{\text {th }}$ c. $\mathrm{AD} ; 12$ - Ukraine; 13 - Chersonesus (first centuries $\mathrm{AD}$ ).

Chernyakhov culture: 14 - Middle Dnieper; 15 - Left-bank Ukraine; 16 - Western Ukraine; 17 - Southern Bug-Tiligul; 18 - Moldova; 19 - Lower Dnieper.

Early Iron Age of Kazakhstan: 20 - Tasmolin culture; 21 - nomads, $6^{\text {th }}-4^{\text {th }} \mathrm{c} . \mathrm{BC}$;

22 - nomads, $4^{\text {th }}-3^{\text {rd }}$ c. BC; 23 - nomads, $3^{\text {rd }}-1^{\text {st }}$ c. BC; 24 - Sargat culture (total series); 25 - Yangshao;

26 - Copto; 27 - Dogee-Baar I ( $6^{\text {th }}-4^{\text {th }}$ c. BC); 28 - Kamensk culture (total series, $\left.3^{\text {rd }}-2^{\text {nd }} \mathrm{c} . \mathrm{BC}\right)$.

Scythian time, Northern Black Sea region: 29 - Left-bank Ukraine; 30 - Right-bank Ukraine;

31 - late period (total series); 32 - Wusun Zhou; 33 - Pazyryk culture (total series); 34 - Arzhan-2 ( $7^{\text {th }}$ c. BC). Pazyryk culture: 35 - Mayma; 36 - Kyzyl-Dzhar.

Tesin culture ( $\left.2^{\text {nd }} \mathrm{c} . \mathrm{BC}-1^{\text {st }} \mathrm{c} . \mathrm{AD}\right)$ : 37 - Black Lake; 38 - Esino; 39 - Kamenka;

40 - Tagar-Tashtyk culture (total series); 41 - Tashtyk culture (total series); 42 - Hun-Sarmatian period of Tuva (total series); 43 - Aymyrlyg XXXI $\left(3^{\text {rd }}-1^{\text {st }}\right.$ c. BC $) ; 44-\operatorname{Kokel}\left(1^{\text {st }} \mathrm{c} . \mathrm{BC}-5^{\text {th }} \mathrm{c} . \mathrm{AD}\right)$;

45 - Hun-Sarmatian period, foothill Altai; 46 - Sakar-Chaga I; 47 - Huns of Mongolia 


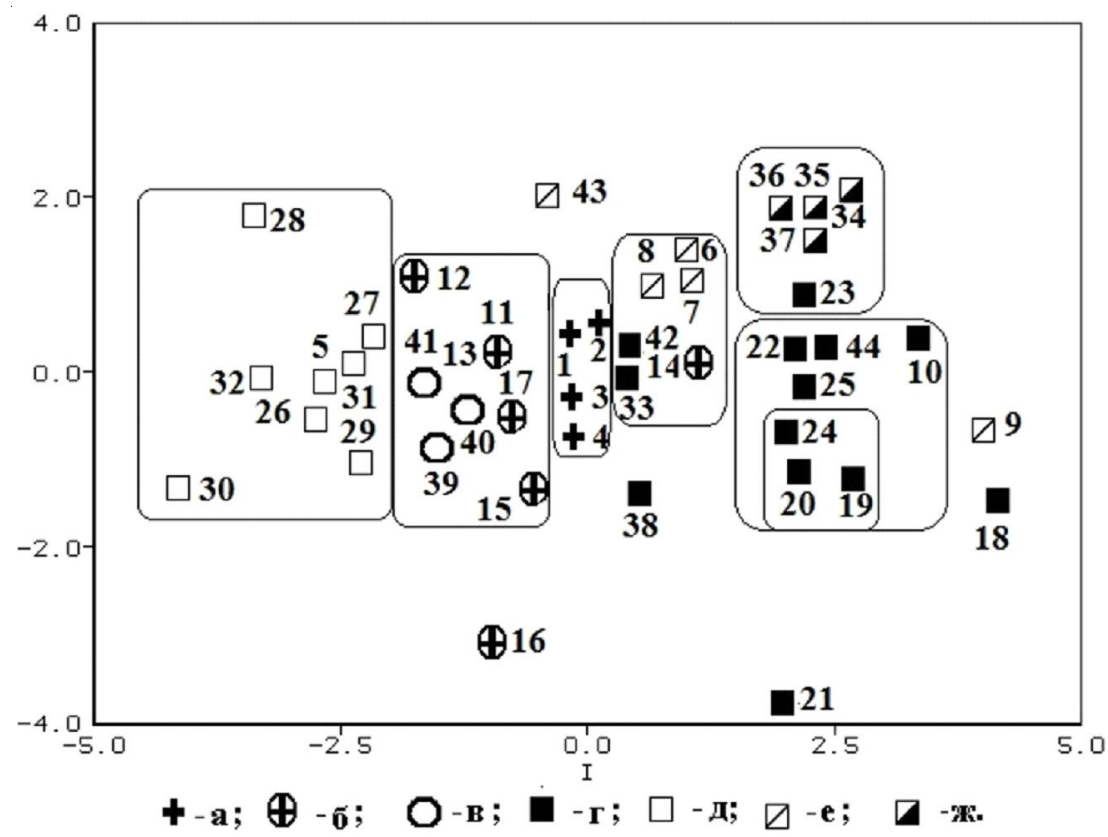

Рис. 3. Результат межгруппового многомерного неметрического шкалирования и кластерного анализа расстояний Махаланобиса $\left(\mathrm{D}^{2}\right) 44$ мужских краниологических серий (обозначения на рис. 1-4 совпадают): Среднесарматские серии: 1 - Нижнее Поволжье, I - первая половина II в. н. э.; 2 - Нижний Дон, І в. до н. э. - I в. н. э.; 3 - Нижний Дон, I-II вв. н. э.; 4 - Украина, I-II вв. н. э.; 5 - Херсонес (первые века нашей эры).

Ранний железный век Казахстана: 6 - кочевники, VI-IV вв. до н. э.; 7 - кочевники, IV-III вв. до н. э.; 8 - кочевники, III-І вв. до н. э.; 9 - тасмолинская культура (сум.); 10 - гунно-сарматское время, Предгорный Алтай (сум.).

Тагарская культура: 11 - подгорновский этап; 12 - биджинский этап; 13 - сарагашенский этап;

14 - тесинское время, склепы; 15 - тесинское время, грунтовые могилы; 16 - могильники таштыкской культуры;

17 - могильники тесинско-таштыкского этапа; 18 - хунны Монголии; 19 - Аймырлыг XXXI (III-I вв. до н. э.);

20 - Кокэль (І в. до н. э. - V в. н. э.); 21 - гунно-сарматское время Тува; 22 - усуни Тянь-Шань; 23 - каменская культура (сум., III-II - начало I в. до н. э.).

Пазырыкская культура: 24 - суммарная серия; 25 - могильники Тянь-Шаня.

Черняховская культура: 26 - Среднее Приднепровье; 27 - Левобережная Украина; 28 - Западная Украина; 29 - Буджак; 30 - Южный Буг-Тилигул; 31 - Нижнее Поднепровье; 32 - Молдавия; 33 - Кызыл-Джар. Саргатская культура: 34 - междуречье Исеть-Тобол; 35 - Приишимье; 36 - Прииртышье; 37 - Бараба; 38 - Кенкольская культура (сум., I-IV вв.).

Скифское время, Северное Причерноморье: 39 - Левобережная Украина; 40 - Правобережная Украина; 41 - поздний период (сум.); 42 -Казыбаба I (VI-IV вв. до н. э.).

Сакская культура: 43 - Сакар-Чага I; 44 - Тянь-Шань

Fig. 3. The result of intergroup multidimensional non-metric scaling and cluster analysis of Mahalanobis distances ( $\left.\mathrm{D}^{2}\right)$ of 44 male craniological series (symbols in Fig. 1 and Fig. 2, 3, 4 match):

Middle Sarmatian series: 1 - Lower Volga region, $1^{\text {st }}-$ the first half of the $2^{\text {nd }} \mathrm{c} . \mathrm{AD}$;

2 - Lower Don region, $1^{\text {st }} \mathrm{c} . \mathrm{BC}-1^{\text {st }} \mathrm{c} . \mathrm{AD} ; 3$ - Lower Don region, $1^{\text {st }}-2^{\text {nd }} \mathrm{c} . \mathrm{AD}$; 4 - Ukraine, $1^{\text {st }}-2^{\text {nd }}$ c. $\mathrm{AD} ; 5$ - Chersonesus (first centuries $\mathrm{AD}$ ).

Early Iron Age of Kazakhstan: 6 - nomads, $6^{\text {th }}-4^{\text {th }} \mathrm{c}$. BC; 7 - nomads, $4^{\text {th }}-3^{\text {rd }} \mathrm{c}$. BC;

8 - nomads, $3^{\text {rd }}-1^{\text {st }}$ c. BC; 9 - Tasmolin culture (total series); 10 - Hun-Sarmatian period, foothill Altai (total series).

Tagar culture: 11 - Podgornovskiy stage; 12 - Bidzhinskiy stage; 13 - Saragashenskiy stage;

14 - Tesin period, crypts; 15 - Tesin period, ground burials; 16 - Tashtyk culture burial grounds;

17 - Tesinsin-Tashtyk stage burial grounds; 18 - Huns of Mongolia; $19-$ Aymyrlyg XXXI $\left(3^{\text {rd }}-1^{\text {st }} \mathrm{c}\right.$. BC);

20 - Kokel (1st century BC - 5th century AD); 21 - Hun-Sarmatian time of Tuva; 22 - Usuni of Tien Shan; 23 - Kamensk culture (total series, $3^{\text {rd }}-2^{\text {nd }} \mathrm{c}$. BC).

Pazyryk culture: 24 - total series; 25 -Tien Shan burial grounds.

Chernyakhov culture: 26 - Middle Dnieper; 27 - Left-bank Ukraine; 28 - Western Ukraine;

29 - Budjak; 30 - Southern Bug-Tiligul; 31 - Lower Dnieper; 32 - Moldova; 33 - Kyzyl-Dzhar.

Sargat culture: 34 - Iset-Tobol interfluve; 35 -Ishim river territory; 36 -Irtysh river territory; 37 - Baraba; $38-$ Kenkol culture (total series, $1^{\text {st }}-4^{\text {th }}$ c. AD).

Scythian period, Northern Black Sea Region: 39 - Left-bank Ukraine; 40 - Right-bank Ukraine; 41 - late period (total series); $42-$ Kazibaba I $\left(6^{\text {th }}-4^{\text {th }} \mathrm{c}\right.$. BC). Sak culture: 43 - Sakar-Chaga I; 44 - Tien Shan 


\section{АРХЕОЛОГИЯ ВОСТОЧНО-ЕВРОПЕЙСКИХ СТЕПЕЙ}

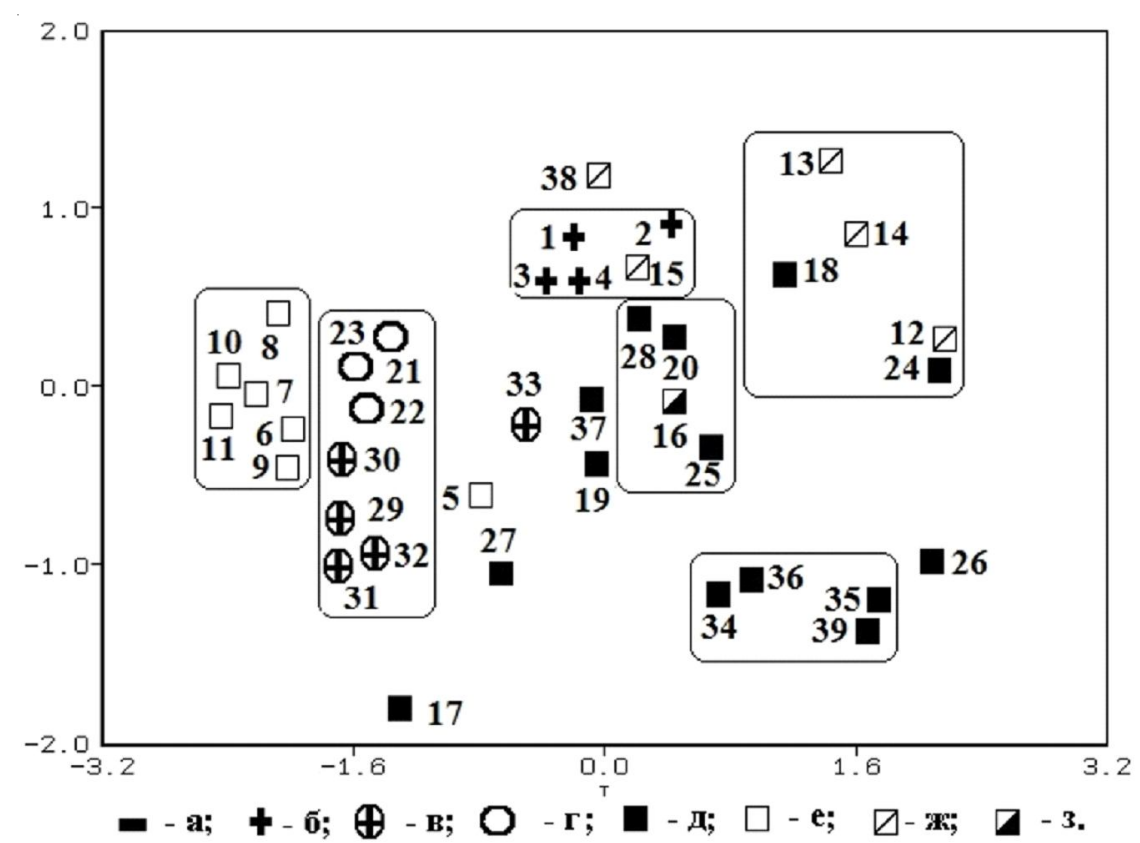

Рис. 4. Результат межгруппового многомерного неметрического шкалирования и кластерного анализа расстояний Махаланобиса $\left(\mathrm{D}^{2}\right) 39$ женских краниологических серий (обозначения на рис. 1-4 совпадают): Среднесарматские серии: 1 - Нижнее Поволжье, I - первая половина II в. н. э.; 2 - Нижний Дон, І в. до н. э. - I в. н. э.; 3 - Нижний Дон, I-II вв. н. э.; 4 - Украина; 5 - Херсонес (первые века нашей эры).

Черняховская культура: 6 - Среднее Приднепровье; 7 - Левобережная Украина; 8 - Западная Украина; 9 - Южный Буг-Тилигул; 10 - Молдавия; 11 - Нижнее Поднепровье.

Ранний железный век Казахстана: 12 - Тасмолинская культура; 13 - кочевники, VI-IV вв. до н. э.; 14 - кочевники, IV-III вв. до н. э.; 15 - кочевники, III-I вв. до н. э.; 16 - саргатская культура (сум.); 17 - Янашао;

18 - Копто; 19 - Догээ-Баары I (VI-IV вв. до н. э.); 20 - каменская культура (сум., III-II - начало I в. до н. э.).

Скифское время, Северное Причерноморье: 21 - Левобережная Украина; 22 - Правобережная Украина; 23 - поздний период (сум.); 24 - могильник Чжоу;

25 - пазырыкская культура (сум.); 26 - могильник Аржан-2 (VII в. до н. э.). Пазырыкская культура: 27 - Майма; 28 - Кызыл-Джар.

Тесинская культура (II в. до н. э. - I в. н. э.): 29 - Черное Озеро; 30 - Есино; 31 - Каменка; 32 - тагарско-таштыкская культура (сум.); 33 - таштыкская культура (сум.);

34 - гунно-сарматское время Тувы (сум.); 35 - Аймырлыг XXXI (III-І вв. до н. э.); 36 - Кокэль (І в. до н. э. - V в. н. э.); 37 - гунно-сарматское время, Предгорный Алтай; 38 - Сакар-Чага I; 39 - хунны Монголии

Fig. 4. The result of intergroup multidimensional non-metric scaling and cluster analysis of Mahalanobis distances $\left(\mathrm{D}^{2}\right)$ of 39 female craniological series (symbols in Fig. 1 and Fig. 2, 3, 4 match):

Middle Sarmatian series: 1 - Lower Volga region, $1^{\text {st }}$ - the first half of the $2^{\text {nd }} \mathrm{c}$. AD;

2 - Lower Don region, $1^{\text {st }} \mathrm{c} . \mathrm{BC}-1^{\text {st }} \mathrm{c} . \mathrm{AD} ; 3$ - Lower Don region, $1^{\text {st }}-2^{\text {nd }} \mathrm{c} . \mathrm{AD}$; 4 - Ukraine; 5 - Chersonesus (first centuries AD).

Chernyakhov culture: 6 - Middle Dnieper; 7 - Left-bank Ukraine; 8 - Western Ukraine; 9 - Southern Bug-Tiligul; 10 - Moldova; 11 - Lower Dnieper.

Early Iron Age of Kazakhstan: 12 - Tasmolin culture; 13 - nomads, $6^{\text {th }}-4^{\text {th }} \mathrm{c}$. BC;

14 - nomads, $4^{\text {th }}-3^{\text {rd }}$ c. BC; 15 - nomads, $3^{\text {rd }}-1^{\text {st }}$ c. BC; 16 - Sargat culture (total series); 17 - Yangshao;

18 - Copto; 19 - Dogee-Baar I $\left(6^{\text {th }}-4^{\text {th }}\right.$ c. BC $) ; 20$ - Kamensk culture (total series, $\left.3^{\text {rd }}-2^{\text {nd }} \mathrm{c} . \mathrm{BC}\right)$.

Scythian time, Northern Black Sea region: 21 - Left-bank Ukraine; 22 - Right-bank Ukraine;

23 - late period (total series); 24 - Wusun Zhou burial ground; 25 - Pazyryk culture (total series); 26 - Arzhan-2 ( $7^{\text {th }}$ c. BC). Pazyryk culture: 27 - Mayma; 28 - Kyzyl-Dzhar.

Tesin culture ( $2^{\text {nd }}$ c. $B C-1^{\text {st }}$ c. AD): 29 - Black Lake; 30 - Esino; 31 - Kamenka; 32 - Tagar-Tashtyk culture (total series);

33 - Tashtyk culture (total series); 34 - Hun-Sarmatian period of Tuva (total series);

35 - Aymyrlyg XXXI $\left(3^{\text {rd }}-1^{\text {st }}\right.$ c. BC); $36-$ Kokel (the $1^{\text {st }}$ c. BC $-5^{\text {th }}$ c. AD);

37 - Hun-Sarmatian period, foothill Altai; 38 - Sakar-Chaga I; 39 - Huns of Mongolia 


\section{СПИСОК ЛИТЕРАТУРЫ}

1. Алексеев, В. П. Краниометрия. Методика антропологических исследований / В. П. Алексеев, Г. Ф. Дебец. - М. : Наука. 1964. - 127 с.

2. Балабанова, М. А. Антропология древнего населения Южного Приуралья и Нижнего Поволжья. Ранний железный век / М. А. Балабанова. М. : Наука, 2000. - 133 с.

3. Балабанова, М. А. Антропология сарматских диагональных погребальных комплексов / М. А. Балабанова // Нижневолжский археологический вестник. - 2002. - Вып. 5. - С. 82-94.

4. Балабанова, М. А. Антропология погребений среднесарматского времени под индивидуальными насыпями / М. А. Балабанова // Сборник материалов Междунар. науч.-практ. конф. «Маргулановские чтения - 2018. Духовная модернизация и археологическое наследие». - Алматы-Актобе : Ин-т археологии им. А.Х. Маргулана, 2018. C. $572-581$.

5. Балабанова, М. А. К антропологическому типу сарматской элиты (по материалам погребений среднесарматского времени Нижнего Поволжья) / М. А. Балабанова // Нижневолжский археологический вестник. - 2018. - Т. 17, № 2. - С. 32-50.

6. Балабанова, М. А. Диагональные погребения как маркер преемственности в сарматских культурах в первые века нашей эры / М. А. Балабанова, М.В.Кривошеев // Нижневолжский археологический вестник. - 2018. - Т. 17, № 1. - С. 50-75.

7. Батиева, Е. Ф. Население Нижнего Дона в IX в. до н. э. - IV в. н. э. (палеоантропологическое исследование) / Е. Ф. Батиева. - Ростов н/Д : Изд-во ЮНЦРАН, 2011. - 160 c.

8. Гинзбург, В. В. Этногенетические связи древнего населения Сталинградского Заволжья (По материалам Калиновского могильника) / В. В. Гинзбург // МИА. - 1959. - № 60. - С. 524-594.

9. Дебец, Г. Ф. Материалы по палеоантропологии СССР. Нижнее Поволжье / Г. Ф. Дебец // АЖ. 1936. -№ 1.- С. 65-80.

10. Дерябин, В. Е. Многомерная биометрия для антропологов / В. Е. Дерябин. - М. : Изд-во МГУ, 1983. - 227 с.

11. Китов, Е. П. Кочевое население Западного Казахстана в раннем железном веке / Е. П. Китов, А. М. Мамедов. - Астана : Изд. группа ФИА им. А.Х. Маргулана в г. Астана, 2014. - 352 с.

12. Кондукторова, Т. С. Материалы по палеоантропологии Украины. Палеоантропологический материал сарматского времени / Т. С. Кондукторова // АС. І. ТИЭ, ХХХІІІ. - М. : [б. и.] ; Л. : Изд-во АН CCCP, 1956. - C. 166-203.

13. Скрипкин, А. С. Кочевой мир юга Восточной Европы во II-I вв. до н. э. (восточные иннова- ции, факты, причины, последствия) / А. С. Скрипкин // Вестник Волгоградского государственного университета. Серия 4, История. Регионоведение. Международные отношения. - 2019. - Т. 24, № 1. C. 20-34.-DOI: https://doi.org/10.15688/jvolsu4.2019.1.2.

14. Фирштейн, Б. В. Сарматы Нижнего Поволжья в антропологическом освещении / Б. В. Фирштейн, Т. А. Тот // Антропологические данные к вопросу о великом переселении народов. Авары и сарматы. - Л. : Наука, 1970. - С. 69-201.

15. 137 Ancient Human Genomes from Across the Eurasian Steppes / P. De Barros Damgaard [et al.]. Electronic text data. - Mode of access: https:// www. nature.com/nature (date of access: 01.02.2019). - Title from screen.

\section{REFERENCES}

1. Alekseev V.P., Debets G.F. Kraniometriya: Metodika antropologicheskikh issledovaniy [Craniometry: Technique of Anthropological Research]. Moscow, Nauka Publ., 1964. 127 p.

2. Balabanova M.A. Antropologiya drevnego naseleniya Yuzhnogo Priuralya $i$ Nizhnego Povolzhya. Ranniy zheleznyy vek [Anthropology of the Ancient Population of the Southern Urals and the Lower Volga Region. Early Iron Age]. Moscow, Nauka Publ., 2000. 133 p.

3. Balabanova M.A. Antropologiya sarmatskikh diagonalnykh pogrebalnykh kompleksov [Anthropology of Sarmatian Diagonal Burial Complexes]. Nizhnevolzhskiy arkheologicheskiy vestnik [The Lower Volga Archaeological Bulletin], 2002, iss. 5, pp. 82-94.

4. Balabanova M.A. Antropologiya pogrebeniy srednesarmatskogo vremeni pod individualnymi nasypyami [The Anthropology of Middle Sarmatian Time Burials Under Individual Mounds]. Sbornik materialov Mezhdunar. nauch.prakt. konf. "Margulanovskie chteniya - 2018. Dukhovnaya modernizatsiya $i$ arkheologicheskoe nasledie» [Collection of Works of the International Scientific and Practical Conference "Margulan Readings - 2018. Spiritual Modernization and Archaeological Heritage"]. Almaty-Aktobe, In-t arkheologii im. A.Kh. Margulana, 2018, pp. 572-581.

5. Balabanova M.A. K antropologicheskomu tipu sarmatskoy elity (po materialam pogrebeniy srednesarmatskogo vremeni Nizhnego Povolzhya) [To the Anthropological Type of the Sarmatian Elite (Based on the Materials from Burial of the Middle Sarmatian Time of the Lower Volga Region)]. Nizhnevolzhskiy arkheologicheskiy vestnik [The Lower Volga Archaeological Bulletin], 2018, vol. 17, no. 2, pp 32-50.

6. Balabanova M.A., Krivosheev M.V. Diagonalnye pogrebeniya kak marker preemstvennosti 


\section{АРХЕОЛОГИЯ ВОСТОЧНО-ЕВРОПЕЙСКИХ СТЕПЕЙ}

v sarmatskikh kulturakh v pervye veka nashey ery [Diagonal Burials as a Marker of Succession of Sarmatian Cultures in the First Centuries AD]. Nizhnevolzhskiy arkheologicheskiy vestnik [The Lower Volga Archaeological Bulletin], 2018, vol. 17, no. 1, pp. 50-75.

7. Batieva E.F. Naselenie Nizhnego Dona v $I X v$. do n.e. - IV v. n.e. (paleoantropologicheskoe issledovanie) [The Population of the Lower Don in the $9^{\text {th }}$ Century $\mathrm{BC}-4^{\text {th }}$ Century AD (Paleoanthropological Study)]. Rostov-on-Don, Izd-vo YuNTs RAN, 2011. 160 p.

8. Ginzburg V.V. Etnogeneticheskie svyazi drevnego naseleniya Stalingradskogo Zavolzhya (po materialam Kalinovskogo mogilnika) [Ethno-Genetic Connections of the Ancient Population of Stalingrad Region (Based on Materials of Kalinovskiy Burial Mound)]. MIA, 1959, no. 60, pp. 524-594.

9. Debets G.F. Materialy po paleoantropologii SSSR. Nizhneye Povolzhye [Materials on Paleoanthropology of the USSR. Lower Volga Region]. $A Z h, 1936$, no. 1, pp. 65-80.

10. Deryabin V.E. 1983. Mnogomernaya biometriya dlya antropologov [Multidimensional Biometrics for Anthropologists]. Moscow, Izd-vo MGU, 1983. 227p.

11. Kitov E.P., Mamedov A.M. Kochevoe naselenie Zapadnogo Kazakhstana v rannem zheleznom veke [The Nomadic Population of Western Kazakhstan in the Early Iron Age]. Astana, Izdat. gruppa FIA im. A.Kh. Margulana v g. Astana, 2014. 352 p.

12. Konduktorova T.S. Materialy po paleoantropologii Ukrainy. Paleoantropologicheskiy material sarmatskogo vremeni [Materials on Paleoanthropology of Ukraine. Paleoanthropological Material of the Sarmatian Time]. AS. I. TIE, XXXIII [Anthropological Collection. I. Proceedings of the Institute of Ethnography, XXXIII]. Moscow, Leningrad, Izd-vo AN SSSR, 1956, pp. 166-203.

13. Skripkin A.S. Kochevoy mir yuga Vostochnoy Evropy vo II-I vv. do n. e. (vostochnye innovatsii, fakty, prichiny, posledstviya) [The Nomadic World of the South of Eastern Europe in the $2^{\text {nd }}$ $1^{\text {st }}$ Centuries BC (Eastern Innovations, Facts, Causes and Consequences]. Vestnik Volgogradskogo gosudarstvennogo universiteta. Seriya 4, Istoriya. Regionovedenie. Mezhdunarodnye otnosheniya [Science Journal of VolSU. History. Area Studies. International Relations], 2019, vol. 24, no. 1, pp. 2034. - DOI: https://doi.org/10.15688/jvolsu4.2019.1.2.

14. Firshteyn B.V., Tot T.A. Sarmaty Nizhnego Povolzhya $\mathrm{v}$ antropologicheskom osveshchenii [Sarmatians of the Lower Volga Region in the Anthropological Illumination]. Antropologicheskie dannye $k$ voprosu o velikom pereselenii narodov. Avary i sarmaty [Anthropological Data on the Peoples' Great Migration. The Avars and the Sarmatians]. Leningrad, Nauka Publ., 1970, pp. 69-201.

15. De Barros Damgaard P., Marchi N., Rasmussen S., Peyrot M., Renaud1 G., Korneliussen T., Moreno-Mayar J.V., Pedersen M.W., Goldberg A., Usmanova E., Baimukhanov N., Loman V., Hedeager L., Pedersen A.G., Nielsen K., Afanasiev G., Akmatov K., Aldashev A., Alpaslan A., Baimbetov G., Bazaliiskii V.I., Beisenov A., Boldbaatar B., Boldgiv B., Dorzhu Ch. Ellingvag S., Erdenebaatar D., Dajani R., Dmitriev E., Evdokimov V., Frei K.M., Gromov A., Goryachev A., Hakonarson H., Hegay T., Khachatryan Z., Khaskhanov R., Kitov E., Kolbina A., Kubatbek T., Kukushkin A., Kukushkin I., Lau N., Margaryan A., Merkyte I., Mertz I.V., Mertz V.K., Mijiddorj E., Moiyesev V., Mukhtarova G., Nurmukhanbetov B., Orozbekova Z., Panyushkina I., Pieta K., Smrèka V., Shevnina I., Logvin A., Sjogren K.-G., Štolcova T., Tashbaeva K., Tkachev A., Tulegenov T., Voyakin D., Yepiskoposyan L., Undrakhbold S., Varfolomeev V., Weber A., Kradin N., Allentoft M.E., Orlando L., Nielsen R., Sikora M., Heyer E., Kristiansen K. \& Willerslev E. 137 Ancient Human Genomes from Across the Eurasian Steppes. URL: https://www.nature.com/ nature (accesed 1 February 2019).

\section{Information about the Author}

Mariya A. Balabanova, Doctor of Sciences (History), Professor, Department of Russian and Foreign History and Archaeology, Volgograd State University, Prosp. Universitetsky, 100, 400062 Volgograd, Russian Federation, mary.balabanova@volsu.ru, https://orcid.org/0000-0002-1565-474X

\section{Информация об авторе}

Мария Афанасьевна Балабанова, доктор исторических наук, профессор кафедры отечественной и зарубежной истории, археологии, Волгоградский государственный университет, просп. Университетский, 100, 400062 г. Волгоград, Российская Федерация, mary.balabanova@volsu.ru, https://orcid.org/0000-0002-1565-474X 